\begin{tabular}{|l|r|}
\hline S sciendo & \begin{tabular}{c} 
NCF $\begin{array}{c}\text { Nordic } \\
\text { Concrete } \\
\text { Federation }\end{array}$ \\
\hline $\begin{array}{l}\text { C) Article authors. This is an open access article } \\
\text { distributed under the Creative Commons Attribution- } \\
\text { licens. }\end{array}$
\end{tabular} \\
$\begin{array}{l}\text { NonCommercial-NoDerivs } \\
\text { (http://creaticecommons.org/licenses/by.nc-nd/3.0/). }\end{array}$ & $\begin{array}{r}\text { ISSN online 2545-2819 } \\
\text { ISSN print 0800-6377 }\end{array}$ \\
\hline & $\begin{array}{r}\text { Received: Sept. 29, 2020 } \\
\text { Rev. received: Dec. 7, 2020 } \\
\text { Accepted: Dec. 14, 2020 }\end{array}$ \\
\hline
\end{tabular}

\title{
Review of Sprayability of Wet Sprayed Concrete
}

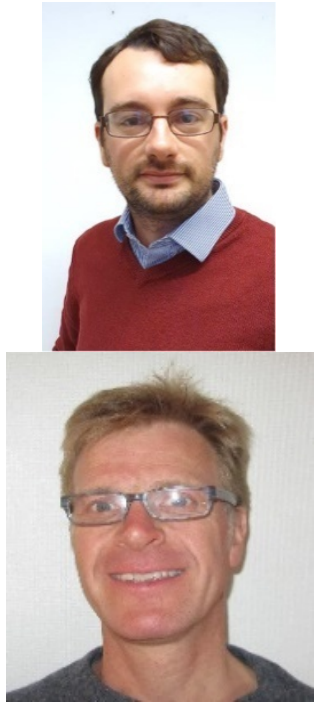

Nicholas Trussell

MEng, CPEng, MIEAust, PhD Student

Norwegian University of Science and Technology,

Department of Structural Engineering,

Richard Birkelands vei 1A, 7034 Trondheim, Norway

E-mail: nicholas.h.trussell@ntnu.no

Stefan Jacobsen

MSc, Dr.Ing, Professor

Norwegian University of Science and Technology,

Richard Birkelands vei 1A, 7034 Trondheim, Norway

E-mail: stefan.jacobsen@ntnu.no

\begin{abstract}
Wet sprayed concrete quality is affected by more production factors than cast concrete, particularly due to the propulsion through the nozzle and the flash set caused by the set accelerator. Practitioners often use the term "sprayability" to describe these factors. We propose a definition of "sprayability" that relates the application to the final properties of the hardened sprayed concrete and review factors affecting it: concrete constituents, proportioning, and application mechanics. These factors affect the hardening and the structure of the hardened sprayed concrete - the porosity, permeability and durability. We consider improving sustainability through proportioning with increased share of supplementary cementitious materials, calculate the placed composition and focus on factors that affect water transport, and hence durability. Due to the spray application and flash-set, irregular compaction voids dominate the macro pore structure of sprayed concrete. Studies of permeability of sprayed concrete have shown that it is possible to obtain low permeabilities given adequate composition and curing. Presumably these samples have been wellcured, uncracked and with non-percolating macro voids. Given observations of cracks in sprayed concrete linings and the macro voids, important further studies will be on the effect of accelerator, compaction porosity and cracking on permeability.
\end{abstract}


Keywords: Sprayed concrete, sprayability, proportioning, accelerator, durability, porosity, permeability.

1.

\section{INTRODUCTION}

Sprayed concrete is concrete that is applied by pumping through a nozzle and is consolidated by the impact of subsequent sprayed particles. Wet sprayed concrete means that a ready mixed concrete is pumped from a hopper to the nozzle where compressed air and accelerator are added so that the wet mix is sprayed and flash-set occurs as it hits the substrate. This is different to conventional concrete, which is applied manually or by pumping through a pipe, and consolidated under gravity and often mechanically by vibration or other forms of compaction. The placement method enables sprayed concrete to be placed in vertical or overhead locations, in irregular geometry, and with little or no formwork [1].

The sustainability of sprayed concrete tunnel linings (SCL) mainly depends on the concrete composition, the volume of concrete used and on the service life.

\section{$1.1 \quad$ Sprayability}

The term sprayability is frequently used to describe sprayed concrete properties. The term sprayability is a European term, whereas the term "shootability" is commonly encountered in North America.

We can refer to a definition for the pumpability of concrete, i.e. how easily concrete can be pumped. Jolin et al [2] defined concrete pumpability as the capacity of a concrete to be mobilised under pressure while maintaining its initial properties. We can develop this definition further: concrete pumpability is the capacity of a concrete to be pressed through pipes and hoses under pressure while maintaining its initial properties.

The properties of concrete are affected by the spray application process due to the addition of accelerator at the nozzle, which increases the early age strength. The final compressive strength of sprayed concrete can be lower than that for cast concrete [3] due to the effect of the set accelerator and the compaction porosity, see further discussion in Sections 4 and 5. So the above definition for sprayability is too simple and we propose the following definition:

Sprayability is the ability of a specific concrete mix to be sprayed and obtain satisfactory production and in-situ properties after pumping, addition of accelerator at the nozzle and spraying with a specific spraying set up and specific settings (pump speed, air pressure, accelerator dosage, spraying distance and angle, nozzle rotation etc).

Sprayability can be considered as a qualitative measurement, defined by a series of defined and measurable criteria:

- Mix composition

- Flow or slump

- Adhesion and cohesion
- Rebound

- Strength gain with time

- Compaction. 
Sprayability is dependent on several processes through the process of producing and applying the sprayed concrete. This starts with the composition of the mix: the mix must be sufficiently flowable to be pumped and sprayed, but sufficiently "stiff" for the sprayed concrete to adhere to the substrate and not fail in cohesion. The sprayed concrete must achieve sufficient "set" to solidify and develop shear strength, and not fall or drip away from the surface as a liquid.

\subsection{Dry or wet process}

For a dry process of sprayed application of concrete, a dry cementitious mixture is transported through a hose to the nozzle, where water is added by the operator. The dry process relies on the skill level of the operator to determine and implement the mixing ratios of the dry mix and water at the nozzle. A schematic diagram showing the dry process for sprayed concrete is presented in Figure 1 [4].

For a wet process the fresh concrete mixture, excluding set accelerator, is fed into the hopper of the spraying machine. From there it is pumped to the nozzle, where compressed air and set accelerator are added. A schematic diagram depicting the wet process for spraying concrete is included in Figure 2. The water content of the fresh sprayed concrete is determined during batching rather than at the nozzle, so the nature and the quality of the final product is less dependent on the skill of the operator.

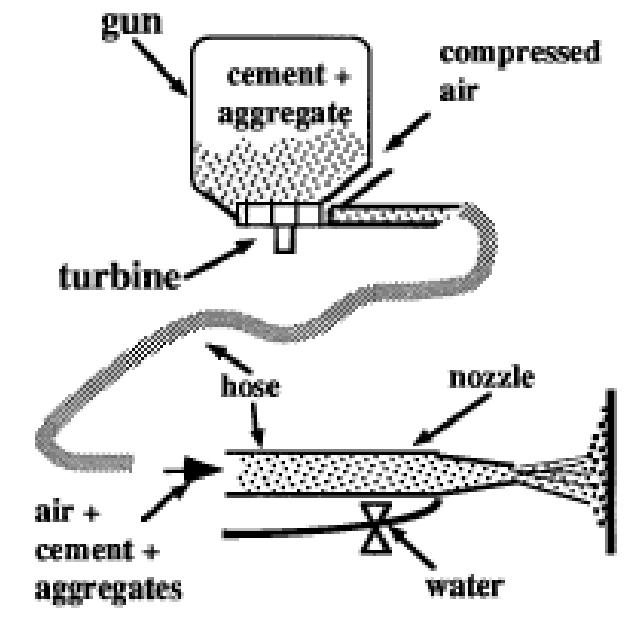

Figure 1 - Diagram of dry process for sprayed concrete [4]

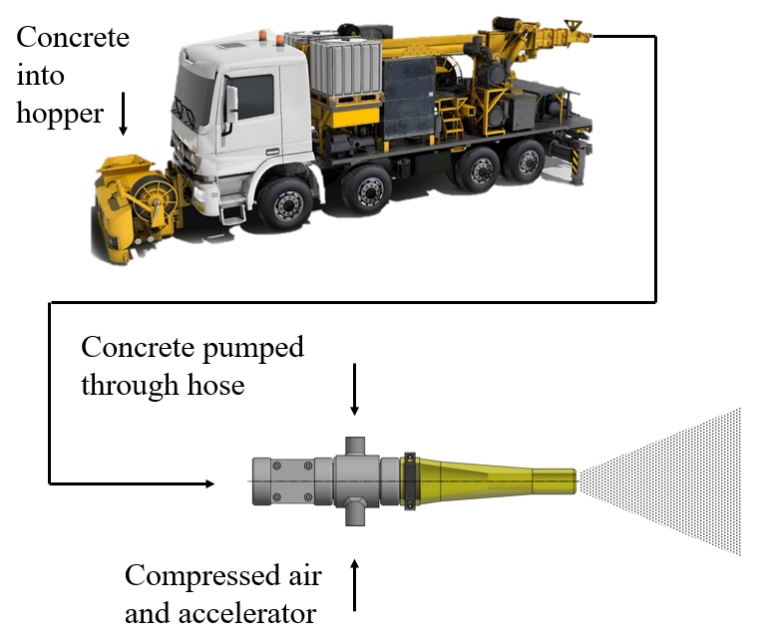

Figure 2 - Diagram of wet process for sprayed concrete

The wet process for sprayed concrete is more common than the dry one and is used for sprayed concrete tunnel linings. Dry process application would be used more for repair works or projects in remote locations, where supply of concrete from batching plant is impractical. As such this study only considers the wet process for sprayed concrete.

\subsection{Scope}

The scope of this paper is to investigate and describe the often-encountered term "sprayability" of concrete and the variables that affect this. Then we give an overview of constituent materials, 
application and central properties of wet sprayed concrete that we believe are essential for the sprayability, with regard to productivity, economy, function, durability and sustainability.

This paper studies the mix composition, rheology, pumping, application, compaction of wet sprayed concrete. Physical properties of the in-situ properties that are related to the quality of application are considered - such as the presence of macro air voids.

Suggestions for investigations to understand sprayability and the essential material properties that affect SCL quality and sustainability are proposed. The outlook for the future of wet sprayed concrete is also discussed, for example ideas for improved durability and sustainability.

2.

MATERIALS, PROPORTIONING AND RHEOLOGY

\section{1}

\section{Constituent materials and proportioning}

Proportioning and rheology of fresh concrete can be modelled by the two-phase particle matrix model (PMM) [5]. The matrix phase consists of water, additives, admixtures and the finest aggregate particles, whilst the particle phase consists of all particles larger than $0.125 \mathrm{~mm}$.

The air voids can be considered as a part of the matrix since workability is assumed to be a function of quality and volume fraction of matrix. A rule of thumb could be that half a litre of air voids could be equivalent to a litre of matrix for workability, per metre volume of concrete. In practical calculation of the two phases the sum must be 1 so air voids can then be placed as part of the matrix, though reported separately in the proportioning:

$$
V_{\text {matrix including air }}+V_{\text {particles }}=1
$$

A typical sprayed concrete mix is detailed in Table 1. A set accelerator is added at the nozzle. In Table 1 we have presented the batched composition and then determined the placed composition due to increased water content from the accelerator and macro voids in the placed composition.

Table 1 - Typical sprayed concrete mix declared by ready mix producer and placed composition corrected for volume change by accelerator added at spraying and compaction porosity after spraying

\begin{tabular}{|c|c|c|c|c|c|}
\hline Phase & Constituent & $\begin{array}{r}\text { Mass } \\
\left(\mathrm{kg} / \mathrm{m}^{3}\right)\end{array}$ & $\begin{array}{r}\text { Volume } \\
\left(1 / \mathrm{m}^{3}\right)\end{array}$ & $\begin{array}{r}\text { Volume } \\
\left(1 / \mathrm{m}^{3}\right)\end{array}$ & $\begin{array}{r}\text { Placed concrete } \\
\text { composition* }\left(\mathrm{kg} \text { per } \mathrm{m}^{3}\right. \\
\text { concrete after spraying) }\end{array}$ \\
\hline \multirow{8}{*}{$\begin{array}{l}\text { Matrix } \\
\text { phase }\end{array}$} & Standard fly ash cement & 462 & 156 & \multirow{8}{*}{424} & 440 \\
\hline & Water & 206 & 206 & & 219 \\
\hline & Silica fume & 19,2 & 8,7 & & 18,3 \\
\hline & Super plasticiser & 4,8 & 4,6 & & 4,6 \\
\hline & Air entrainment agent & 0,45 & 0,45 & & 0.43 \\
\hline & Set accelerator (dry) & - & - & & 24,8 \\
\hline & $\begin{array}{l}0-8 \mathrm{~mm} \text { aggregate }(<0.125 \\
\mathrm{mm})\end{array}$ & 21,8 & 8,3 & & 20,8 \\
\hline & Air & & 40 & & 65 \\
\hline \multirow{2}{*}{$\begin{array}{l}\text { Particle } \\
\text { phase }\end{array}$} & $\begin{array}{l}0-8 \mathrm{~mm} \text { aggregate }(>0.125 \\
\mathrm{mm})\end{array}$ & 1505,8 & 570,4 & \multirow[t]{2}{*}{576} & 1435 \\
\hline & Steel fibres & 45 & 5,6 & & 42,9 \\
\hline
\end{tabular}


* The placed concrete composition is calculated from the mass and volume in the first two columns in two steps:

1) Correct the mass of constituents to $\left(\mathrm{kg} / \mathrm{m}^{3}\right)$ due to increased volume by $10 \%$ accelerator of effective binder mass $=+24 \mathrm{~kg}$ of water. The dissolved chemicals of the accelerator are assumed to have no volume.

2) Correct the mass of constituents to $\left(\mathrm{kg} / \mathrm{m}^{3}\right)$ due to final, sprayed macro void content, for example $6.5 \%$ macro voids, i.e. $2.5 \%$ more air voids than declared by the ready-mix concrete producer at batching.

The purpose of the air entrainment agent is to improve the workability of the fresh concrete. This is thought to work by the ball bearing effect of air voids in the fresh concrete. These air voids are believed to be ejected upon impact of the sprayed concrete with the substrate, and the removal of this entrained air reduces the workability of the concrete. Air entraining agents are thus assumed to increase the workability to improve performance during pumping and spraying, whilst reducing the workability after impact with the substrate, improving stability during hardening [1].

A retarder may be added to delay set time and achieve a longer duration of full workability.

For sprayed concrete the maximum aggregate size is typically $6-8 \mathrm{~mm}$. This aggregate size, smaller than for conventional concrete, improves the performance of the concrete under spraying and pumping. Furthermore smaller aggregate sizes reduce the amount of rebound compared with larger aggregate sizes [6].

Structural fibres are generally included in the sprayed concrete mix. The structural fibres give the concrete ductility and tensile strength and replace conventional reinforcement. Structural fibres can either be steel or macro-polymer fibres. Only steel fibres are considered for this review, because macro-polymer fibres are now banned for use in sprayed concrete linings for Norwegian road tunnels for environmental reasons, as described by Myren et al [7].

The particle matrix model will be useful to investigate how to:

- Increase the use of supplementary cementitious materials such as fly ash or limestone filler,

- Reduce cement content to make more environmentally friendly sprayed concrete mixes,

- Add fillers and other mineral additives whilst keeping matrix volume constant to maintain workability. 
Nordic Concrete Research - Publ. No. NCR 63 - ISSUE 2 / 2020 - Article 2, pp. 21-41

Table 2 - Example of sprayed concrete mix with reduction of cement content by use of fly ash and filler

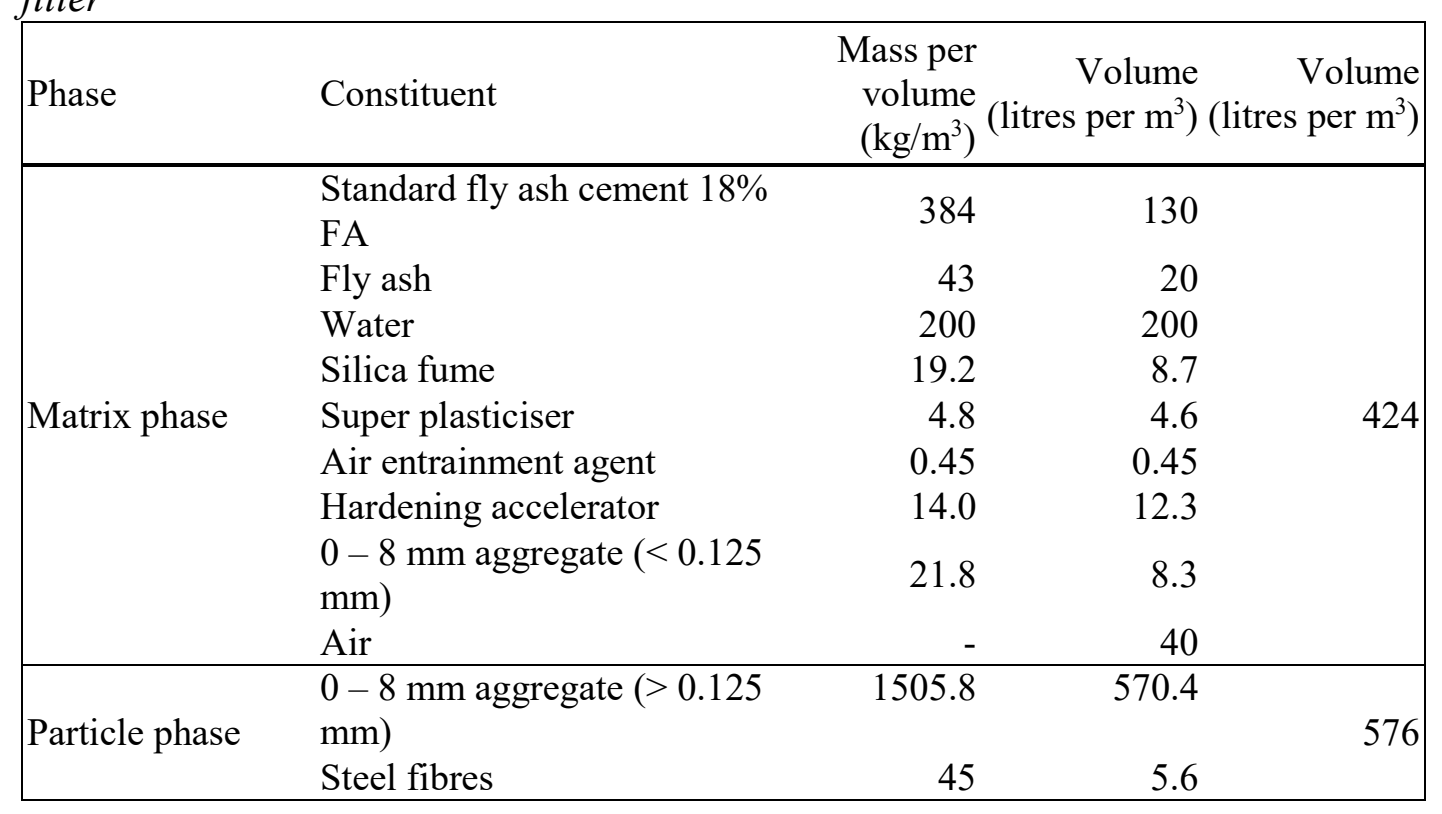

Limestone powder and other fillers, for example from manufactured sand and crushed aggregate, would be good alternatives for filler to be investigated in sprayed concrete studies.

Table 2 provides details on proportioning for two variations of a standard sprayed concrete mix, based on the ready-mix proportions in Table 1 . The cement content is reduced by adding fly ash. Hardening accelerator is added to compensate for the low early age strength development of high fly ash concrete [9].

\section{2}

Rheology

Rheology is defined as "the science of the deformation and flow of matter" [10]. But why is the rheology of the fresh concrete important? Clearly if concrete cannot be pumped from the hopper of the spraying machine to the nozzle, neither can it be sprayed. Kaplan et al [11] determined the range of fresh concrete properties across which concrete can be pumped through a pipe. The criteria that Kaplan determined included the slump of the fresh concrete, stability such as bleed tendency and aggregate size. Perhaps we can infer a similar range of properties at which concrete can be sprayed.

The rheology of concrete can be measured by using a viscometer, which consists of a cylindrical array of steel ribs that is placed into a cylinder that is filled with the concrete to be tested. As the cylinder filled with concrete rotates, the torque versus speed is recorded. This enables the shear stress vs the rate of shear to be plotted for the fresh concrete. The yield shear stress and plastic viscosity can then be derived. A diagram of a concrete viscometer is included in Figure 3. 


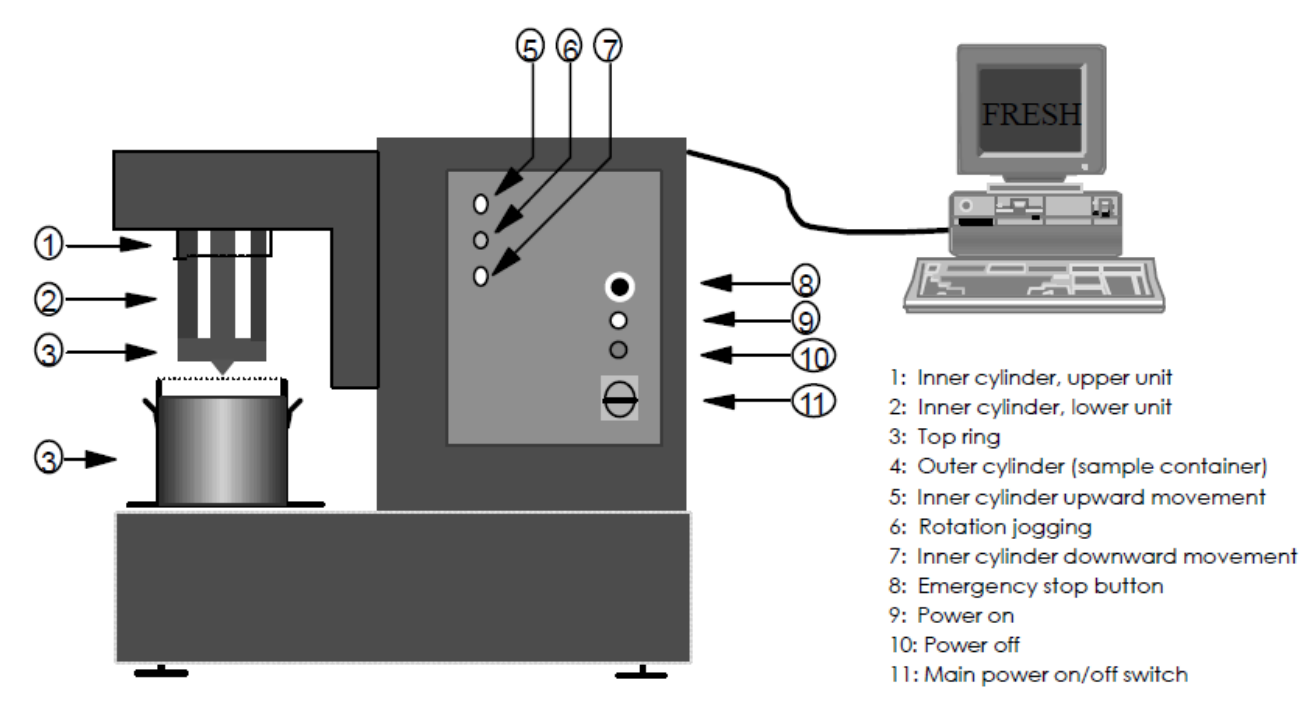

Figure 2 - Concrete viscometer [12]

According to the particle matrix model the rheology of the concrete is governed by:

- The properties of the particles,

- The properties of the matrix,

- The volume ratio of matrix phase/particle phase.

But is the rheology of the concrete important once the sprayed concrete has left the nozzle? Does the rheology of the sprayed concrete effect the adhesion to the application surface, or the cohesion of the freshly sprayed concrete?

Beaupré [4] measured build up thicknesses for different sprayed concrete mixes, measuring the thickness of sprayed concrete that was sprayed onto the application surface whilst keeping the nozzle stationary, before the in place sprayed concrete fell under its own weight. Beaupré determined a relationship between build up thickness and yield stress - the concrete was able to be built up in thicker layers with higher yield stress of the concrete [4]. He also calculated minimum yield stress to avoid fall out under shear stress caused due to self-weight of the sprayed concrete [4]. Note that Beaupré termed the yield stress "flow resistance of the fresh concrete", though still following the Bingham flow model [10] for simple concrete viscometers:

$$
T=g+h N
$$

with $\begin{array}{r}T \\ g \\ h \\ \\ N\end{array}$

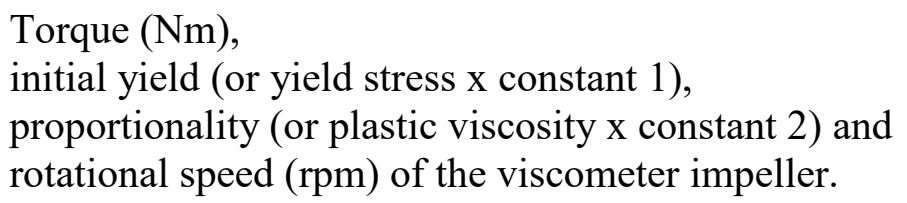

\subsection{Workability}

The workability of fresh concrete is a practical term used to describe the most important properties of fresh concrete: stability, ability to flow by gravity and ability to be compacted and let out encapsulated air. 
Standard practice is to perform a flow test [13] or slump test [14] for each batch of sprayed concrete before application. Both tests are simple procedures and can be readily undertaken in a small area of a construction site or concrete mixing plant.

The purpose of either is to test the concrete is sufficiently flowable to be pumped and sprayed, but stiff enough to adhere to the application surface and not fail in cohesion. Stability can be assessed by looking at the edge of the pancake for bleeding and at the centre to look for segregation of the coarse particles.

Based on our preliminary observations of the spraying of a batch of concrete, which experienced a workability loss over a time of more than two hours while varying the accelerator from 0 to $10 \%$ of the binder mass, we think accelerator variation has a greater effect on sprayability than varying workability.

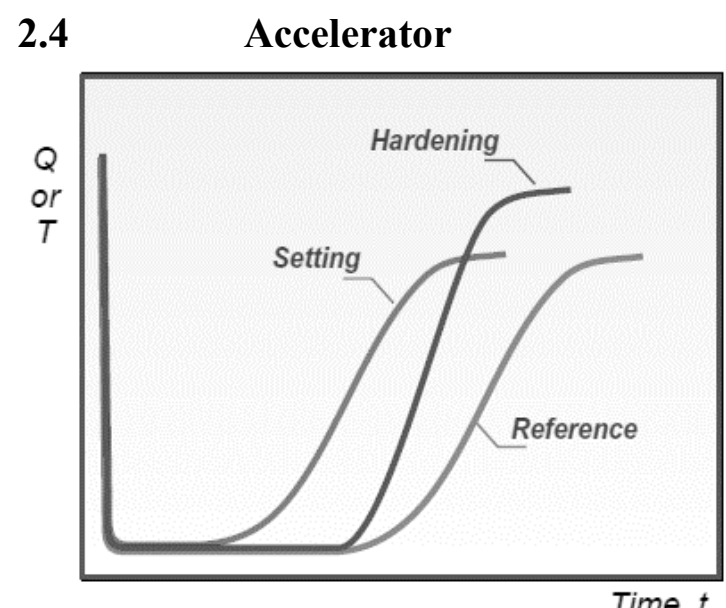

Figure 4 - The effects of setting and hardening accelerators on the rate of heat evolution [15]

Accelerators for concrete fall into two categories:

- Setting accelerators are applied at the nozzle and produce an earlier initiation of hydration of the cement.

- Hardening accelerators are incorporated into the mix and increase the rate of hydration of the cement, once the reaction has initiated.

The effect of these two types of accelerator is shown in Figure 4 [15].

\subsubsection{Set accelerator}

Set accelerator is normally added at the nozzle to reduce the set time of the sprayed concrete and enabling thickness of the sprayed concrete to build up on the application surface. Use of accelerator is particularly important when applying sprayed concrete to the sides and crown of tunnel sections, where the sprayed concrete would run off or fall from the substrate without accelerator. Set accelerator increases the rate of strength development of the sprayed concrete, which is described in Section 4.1.

The set accelerator dosage is controlled by the operator and typical dosages can range from $2 \%$ to $10 \%$ of binder mass. For example a low dosage may be selected when spraying onto the invert of a tunnel, whereas a higher dosage would be desirable when spraying onto the tunnel crown, enabling a faster strength development and hence reducing the likelihood of a fall of the sprayed concrete. 
Due to the addition of the accelerator at the nozzle and the compaction porosity, the placed concrete has a different composition to the batched concrete. The additional water content $\Delta w$ was calculated for the concrete proportioned in Table 1 after the addition of varying dosages of a set accelerator, with $48 \%$ water content, at the nozzle.

$\Delta w=$ accelerator dosage $\mathrm{x}$ accelerator water content $\mathrm{x}\left(m_{c}+k m_{s}\right)$

New $m_{w} /\left(m_{c}+k \cdot m_{s}\right)=(206+\Delta w) / 500$

$\underline{0 \% \text { accelerator }}$

$m_{w} /\left(m_{c}+k \cdot m_{s}\right)=206 / 500=0.412$

$3 \%$ accelerator

$\Delta w=0.03 \times 0.48 \times(500)=7.2 \mathrm{~kg}$

$m_{w} /\left(m_{c}+k . m_{s}\right)=(206+\Delta w) / 500=0.426$

where

\section{$6 \%$ accelerator}

$\Delta w=0.06 \times 0.48 \times(500)=14.4 \mathrm{~kg}$

$m_{w} /\left(m_{c}+k \cdot m_{s}\right)=(206+\Delta w) / 500=0.441$

$10 \%$ accelerator

$\Delta w=0.10 \times 0.48 \times(500)=24.0 \mathrm{~kg}$

$m_{w} /\left(m_{c}+k . m_{s}\right)=(206+\Delta w) / 500=0.460$

\subsubsection{Hardening accelerator}

Hardening accelerator can be incorporated into the mix to compensate for the lower rate of strength development that occurs when fly ash is incorporated into the mix. Hardening accelerators are incorporated into the mix and increase the rate of hydration of the cement, without changing the initial reaction time (see Figure 4) [15]. Recently hardening accelerators been used in sprayed concrete with high volume of fly ash [9].

Incorporating fly ash into the concrete proportioning, whilst reducing the rate of early strength development, increases the final strength of concrete due to the pozzolanic reaction. The silica in the pozzolan reacts with the calcium hydroxide, which is a by-product of cement hydration, to produce more calcium silicate hydrate $(\mathrm{CSH})$. This pozzolanic reaction, though increasing the amount of gel and hence gel porosity, reduces the capillary porosity, which reduces water transport through the concrete and hence improves durability. Long term strength is also increased due to the reduced capillary porosity and higher CSH content.

3.

\section{SPRAY APPLICATION}

\section{1}

\section{Pumping}

When concrete is pumped from the hopper to the nozzle through pipes, coarser particles migrate towards the centre of the flow, whilst a layer of paste, formed from smaller particles, forms around the pipe wall. This paste can be referred to as a lubrication layer and a schematic picture is shown in Figure 5 [16]. 


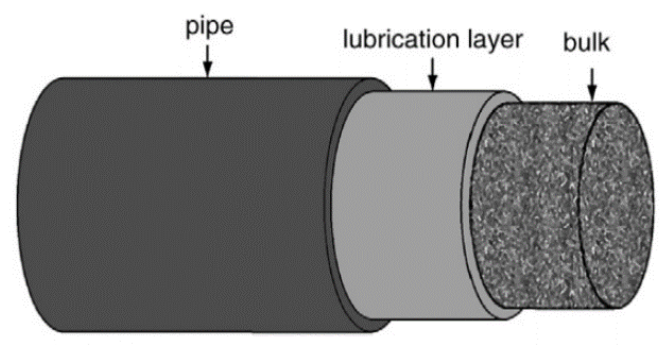

Figure 5 - Schematic of concrete flow in pipe, reproduced from Choi [16], showing lubrication layer during concrete pumping

Choi [16] measured the thickness of this layer as approximately $2 \mathrm{~mm}$, for concrete flow through a plastic pipe of $125 \mathrm{~mm}$ diameter. For concrete spraying equipment, the concrete line to the nozzle is through a rubber hose. A rubber hose will have a rougher intrados than a smooth plastic pipe. It is therefore anticipated that the thickness of the lubrication layer would be greater for the flow of pumped concrete through the rubber hose, compared to the $2 \mathrm{~mm}$ thickness measured by Choi.

\section{2}

\section{Mixing at the nozzle}

Sprayed concrete is pumped to the nozzle, where it is mixed with pressurised air and accelerator, and discharged through the nozzle. A typical schematic of the interactions at the nozzle is presented in Figure 6. Blockages at the nozzle can occur. The cause of this is likely to be the concrete gaining cohesion during pumping and upon addition of accelerator, and hence clogging the nozzle.

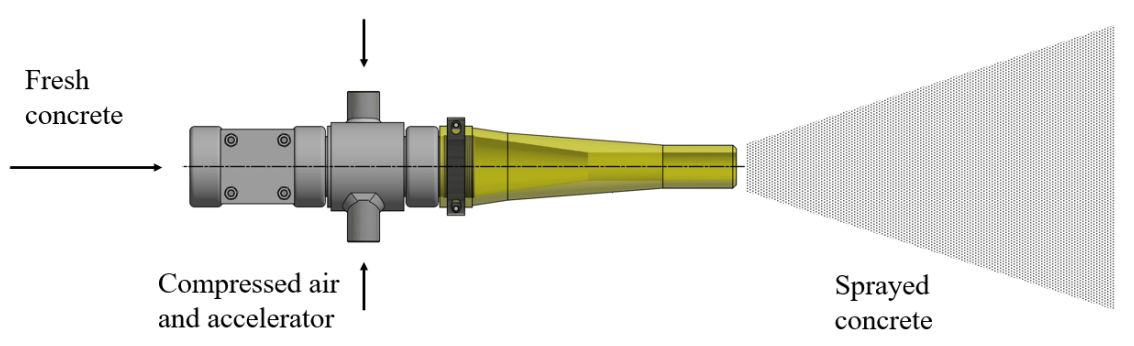

Figure 6 - Typical diagram showing interactions between pressurised air, accelerator and sprayed concrete

\subsection{Application mechanics}

The quality of sprayed concrete is, to a great extent, determined by the actions of the operator, who can affect the application parameters, notably distance and angle between spray and substrate, movement of the nozzle, ratio between concrete and air flow, and accelerator dosage. It has been demonstrated by Ginouse and Jolin [17] that there is a greater mass flux density at the centre of the spray cone than at the edges, as shown in Figure 7. Furthermore, there is a different material content throughout the spray cone - there is a migration of aggregate and larger particles towards the centre of the spray cone, whereas at the edge of the spray cone there is a higher proportion of concrete paste or matrix. This is perhaps an extension of the lubrication layer effect in the pipe flow, where the coarse particles migrate towards the centre of the pump line flow, 
described Section 3.1. So the flow conditions of concrete in the hose before reaching the nozzle likely affect the composition and material distribution in the spray cone.

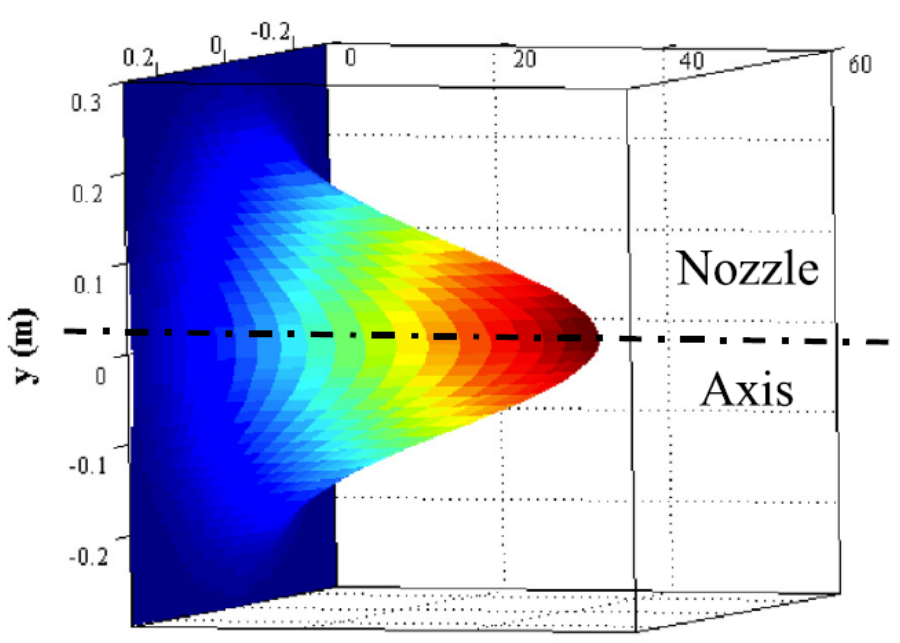

Figure 7 - Max flux density of spray cone [17]

To ensure consistent mass and particle distribution throughout the sprayed concrete, the operator often articulates the nozzle in small circular motions. Ginouse and Jolin [17] opined that the circular motions and particle distribution ensure that paste-rich material is always deposited immediately before larger particles and fibres hit the surface. The paste and fine particles provide better encapsulation for the larger particles and the fibres and enable better retention, hence reducing rebound from the spray application. The final effect of this on compaction is hard to judge in our opinion since little information exists on the sequence of events and movement through the different phases, impact, compaction and rate of set at impact.

The distance of the nozzle from the application surface is an important parameter. A study by Ginouse et al [17] measured the velocity of particles greater than $5 \mathrm{~mm}$ diameter and these were found to accelerate over distances $0.5-1.0 \mathrm{~m}$ from the nozzle. At smaller distances the spray area is narrower, due to the total cone angle of 24.5 degrees for wet spraying reported by Ginouse et al [18]. Ginouse et al [18] also measured an influence of gravity in the spray cone - for a horizontal application of sprayed concrete, they measured a slightly greater flux density below the horizontal axis.

Ginouse \& Jolin [19] used a high-speed camera to observe speed of particles greater than $5 \mathrm{~mm}$ from a nozzle with $32 \mathrm{~mm}$ outlet diameter during wet spray. They measured 26 and $28 \mathrm{~ms}^{-1}$ in the centre of the spray cones at 0.5 and $1 \mathrm{~m}$ distance. The speed towards the edge of the cone dropped to around $20-22 \mathrm{~ms}^{-1}$.

Opsahl [20] sprayed on a wheel arrangement $0.2 \mathrm{~m}$ in front of a $1 \frac{1}{2}$ inch nozzle and observed $32-$ $35 \mathrm{~ms}^{-1}$ exit velocity. Though perhaps the wheel arrangement was affected by the compressed air itself as well as the impact of the particles.

Reinhold and Wetzig [21] conducted concrete spraying experiments and determined that the variations in the nozzle distance and air flow rate did not significantly affect the in-situ properties of sprayed concrete. 
The nozzle should be perpendicular to the application surface, as specified by [22]. Perpendicular application is important to improve compaction and reduce rebound. Although the irregular surfaces of blasted tunnels have relatively large roughness, so perpendicular application is impossible in practice when combined with the rotational movement.

\section{4}

\section{Rebound}

Rebound is an unavoidable by-product of the sprayed application of concrete and occurs when spray-applied material fails to adhere to the substrate and instead falls to the ground. Reference [22] reports that rebound material for today's sprayed concrete technology is measured as $5 \%$ or less.

The rebound material does not have the same particle distribution as the sprayed concrete mix there is a larger percentage of aggregate and steel fibres. Kaufman et al [23] measured the amount of fibre (both steel and polymer fibres were measured) rebound as $25-44 \%$ of the fibre content of the concrete mix. They also observed that coarse aggregate was over-represented in the rebound, though not as much as that of the fibres. Thus the placed fibre content of the sprayed concrete is significantly reduced compared to that of the mix composition.

\subsection{Adhesion and cohesion}

Sprayed concrete applied onto a substrate must achieve sufficient adhesion to the substrate to avoid falling, and sufficient cohesion to avoid falling or slumping under its own weight. The cohesion of sprayed concrete can be measured in terms of the build-up thickness, i.e. how much thickness can be applied before the sprayed concrete falls under self-weight. Austin et al [24] measured build up thicknesses of 130-320 mm for different mix designs in laboratory tests.

Adhesion is controlled by two factors:

- the nature of the substrate, and

- the shear strength of the sprayed concrete.

The surface onto which the sprayed concrete is to be applied should be clean, moist and free from dust and loose material prior to application. The methods for cleaning the surface are described in [22]. Cleaning by jet wash with water is the most common surface preparation measure. 


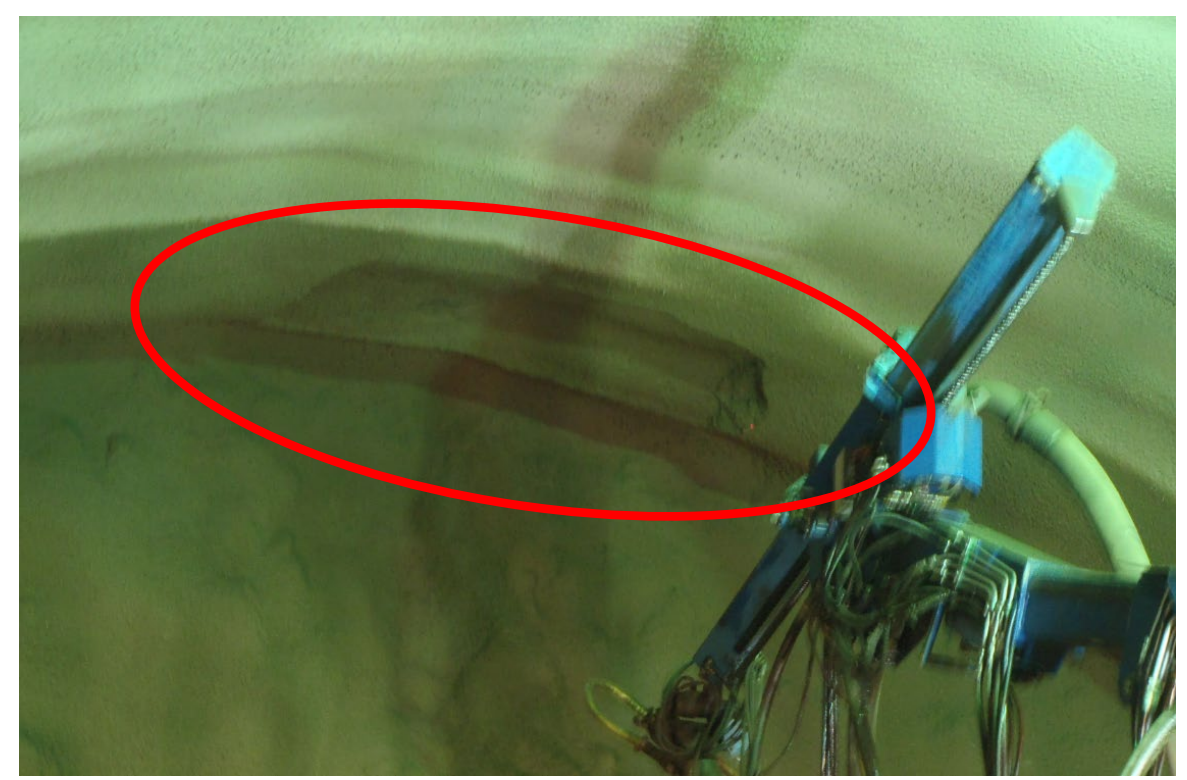

Figure 8-Photograph showing area where sprayed concrete has fallen from tunnel crown, cause unknown but likely sprayed concrete failed under own self-weight (photograph Nicholas Trussell)

\section{4.}

\section{HARDENING}

\section{1}

\section{Strength development}

Early age strength of sprayed concrete is the main quality criterion for immediate rock support. It allows the necessary progress, safety and quality during construction of sprayed concrete tunnels and reduces the likelihood of falls of loose rock or sprayed concrete during, or immediately after, application. In [25] the requirements to strength over time are given as classes, see Figure 9. The $\mathrm{J}$ is from the German word jung, meaning young, and $\mathrm{A}, \mathrm{B}$ and $\mathrm{C}$ are the boundaries between the $J_{1}, J_{2}$ and $J_{3}$ strength classes.

Early age strength is tested by penetrometer for strengths typically up to one or two hours. At higher strengths (from 3 hours to 24 hours) the Hilti stud driving test is used. 28 day and longerterm strength is tested by laboratory crushing of core samples.

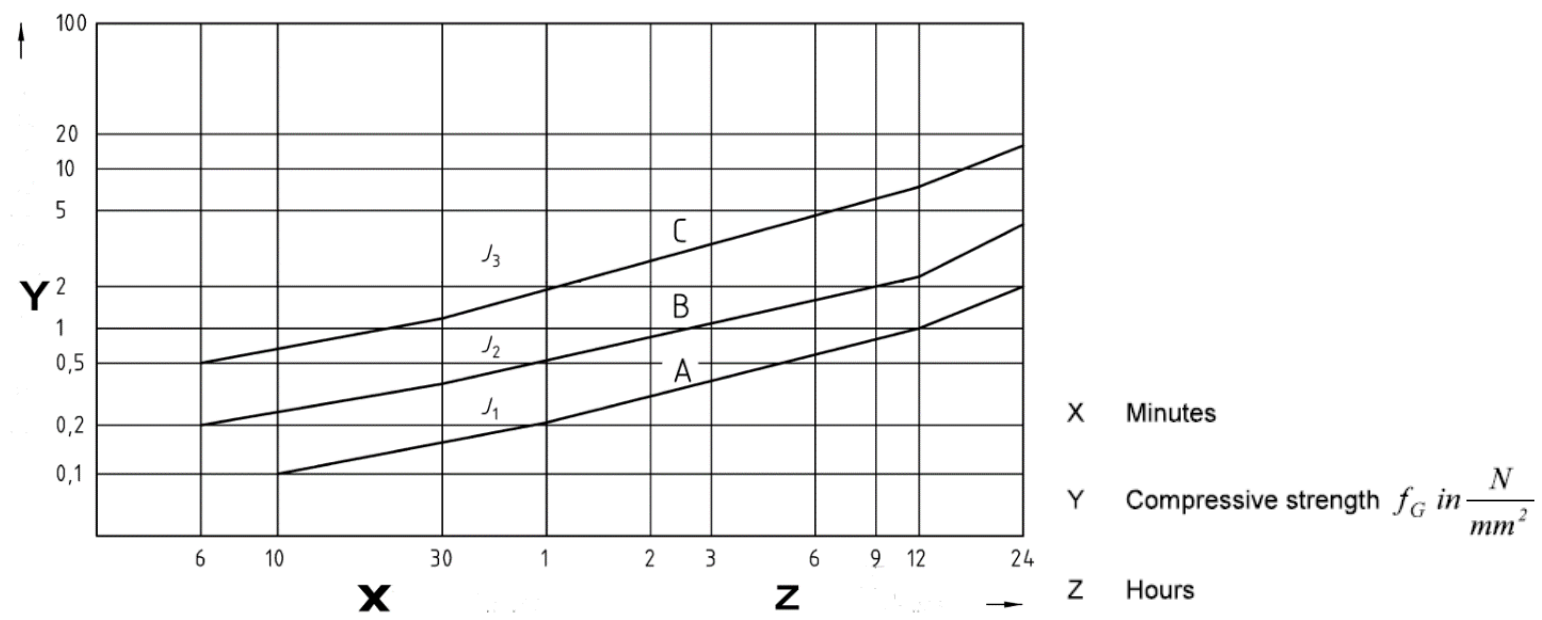

Figure 9 - Early age strength curves for sprayed concrete [25] 
The high early strength gain is due to the effect of the set accelerator. However higher early age strength can reduce long term compressive strength in a similar way to high temperature early curing. A balance between early age and long-term strength should be achieved.

Neville [26] reported that higher temperature during and following the initial contact between cement and water reduces the length of the dormant period and leads to a coarser structure of the $\mathrm{CSH}$ gel with a higher porosity. A higher porosity leads to a lower long-term strength, as discussed in Section 5.1. Given that the set accelerator reduces the dormant period (as shown in Figure 10) for hydration, we suspect that this yields a coarser structure of the CSH gel (and/or perhaps capillary) porosity in the same way.

Opsahl [20] reported strength loss up to $50 \%$ with a $12 \%$ dosage of alkaline accelerator. Usually there are limits to the recommended dosage beyond which the accelerator can have a detrimental effect on the long-term strength.

\subsection{Temperature development}

The hydration of Portland cement generates approximately $500 \mathrm{~kJ} / \mathrm{kg}$ [27] for complete hydration. Figure 10 shows how $3 \%$ by cement mass of alkaline accelerator and $7 \%$ by cement mass of alkali-free accelerator paste affect isothermal calorimeter curves for hydration of $100 \mathrm{~g}$ of cement [28]. Figure 10 shows how the dormant period was far briefer and the acceleration period of cement hydration occurred much sooner for the accelerated cement pastes.

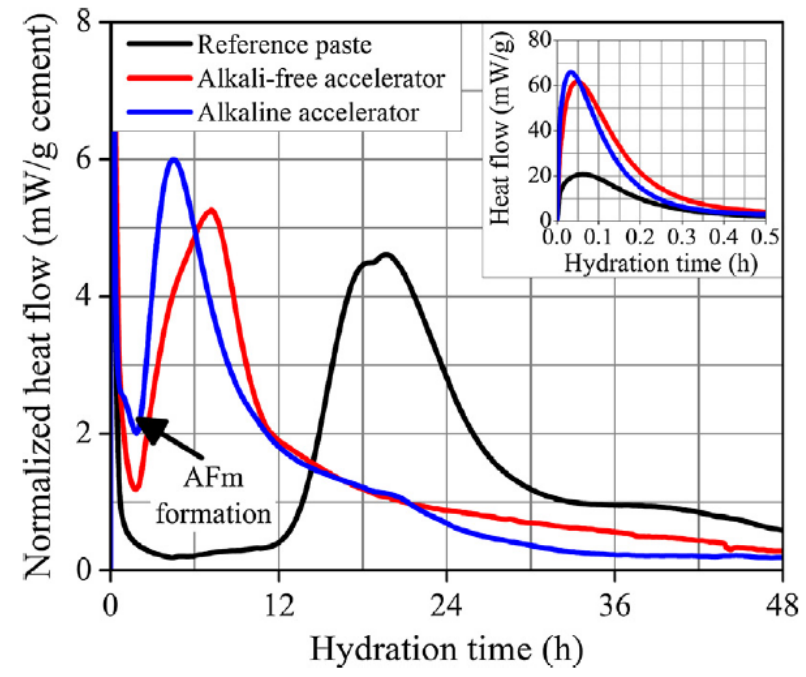

Figure 10 - Heat flow curves of hydration of cement pastes and effect of sprayed concrete accelerators [28]

Beck [29] measured early age strength gain whilst varying the ambient temperature and temperature of the fresh sprayed concrete. It was found that the initial temperature of the sprayed concrete and initial ambient temperature affect the rate of hydration of the cement in the same way as for conventional concrete.

Cepuritis [30] developed a test method for mixing cement paste with accelerator to test the set time of the paste. The test involves manually mixing cement paste with accelerator in a small container. The set time is then determined using the Vicat apparatus [31]. The needle is lowered into contact with the cement and then allowed to fall freely. The cement is considered set once 
the Vicat needle is withdrawn and is clean from cement. This test is applicable to give an indication of the early age strength development of sprayed concrete.

\section{3}

\section{Shrinkage and cracking in-situ}

Concrete experiences volume changes during early age and curing. There is plastic shrinkage due to evaporation of water from fresh concrete, autogenous shrinkage due to hydration, temperature variations and chemical shrinkage, and drying shrinkage due to loss of water from the hardened phase. Internal tensile stresses develop which are resisted by the bond to the substrate. If shrinkage is great enough, the sprayed concrete will crack or debond [32].

Shrinkage of concrete, $\varepsilon_{c}$, is a function of volume of paste, $V_{p}=\left(1-V_{t}\right)$ where $V_{t}=$ volume fraction of aggregate and $\varepsilon_{p}=$ shrinkage of the paste. So a high volume fraction of cement paste $\left(1-V_{t}\right)$ will lead to higher shrinkage.

$$
\begin{aligned}
& \varepsilon_{\mathrm{c}}=\varepsilon_{\mathrm{p}}\left(1-V_{t}\right)^{n} \\
& \text { with } n=1.2-1.7
\end{aligned}
$$

The term "plastic shrinkage" does perhaps not apply to sprayed concrete because, due to the flash set of cement caused by addition of the set accelerator at the nozzle, the concrete is not in the plastic state after application. To our knowledge there is little information about the evolution of shrinkage stresses in sprayed concrete, especially at early age.

Opshal [20] measured free drying shrinkage at $50 \%$ relative humidity on beams cut from sprayed panels at 6 days, then measured from 7 days to 360 days. He observed shrinkage up to $0.7 \times 10^{-3}$ for sprayed concrete samples with $450 \mathrm{~kg} / \mathrm{m}^{3}$ cement content and water/cement ratio of 0.44 . He hence concluded that sprayed concrete behaves in a normal way with respect to drying shrinkage in that period. He found that the presence of steel fibres in the sprayed concrete did not affect the shrinkage.

Holter [33] measured crack widths and spacings in the lining of the Gevingås rail tunnel. The lining was sprayed directly onto the rock and his observations were made a year after spraying. Holter [33] mapped approximately 210 cracks and determined most common crack spacing of $0.7-1.0 \mathrm{~m}$ with most crack widths between 0.05 to $0.5 \mathrm{~mm}$. Distributing the crack widths over the spacing corresponds to strains in the order of $0.05 \times 10^{-3}$ to $0.5 \times 10^{-3}$. Holter [33] observed typically $6{ }^{\circ} \mathrm{C}$ variation of the temperature of the lining over the year. Compared to a thermal expansion coefficient of approximately $10^{-5}{ }^{\circ} \mathrm{C}^{-1}$ this $6^{\circ} \mathrm{C}$ decrease of temperature corresponds to a free deformation of $0.06 \times 10^{-3}$. When compared to a tensile fracture strain of concrete of $0.1 \times 10^{-3}$ to $0.2 \times 10^{-3}$ it appears likely that shrinkage is the most important cause of the cracking.

In the literature there are a few studies on shrinkage of sprayed concrete but few/none of these concern direct measurements of shrinkage of wet sprayed concrete tunnel linings. Bryne et al [34] studied restrained shrinkage by casting sprayable concrete into a ring test, on an instrumented granite slab and by modelling. They studied early age shrinkage up to a few weeks and found that glass fibres could be used to reduce cracking. Menu et al [35] also compared modelling with measurements of shrinkage up to some weeks. Further investigation is therefore needed into shrinkage of sprayed concrete. 
Current sprayed concrete methods produce a less compacted and less consistent concrete than cast concrete - hardened sprayed concrete contains many small and larger air voids, or macro pores. A photograph of an example core from sprayed concrete is shown in Figure 11 where macro pores larger than $1 \mathrm{~mm}$ can be seen on the core surface.

Holter [33] used the capillary suction method [36] and the PF (pore ratio) method [37] to measure porosity of sprayed concrete samples from the Harangen road tunnel. Holter determined suction porosity as around $20 \%$, mean open macro porosity of $0.5 \%$ and closed macro porosity of $4.2 \%$. The open macro porosity was defined as the increase in water uptake from the end point of the one-sided capillary suction curve to a constant mass after subsequent submersion at atmospheric pressure of the same concrete specimens, whereas the closed macro porosity is measured by pressure saturation in the PF test after submersion at atmospheric pressure. In Holter's experiments the open macro porosity made up $11 \%$ of the total macro porosity $0.5 /(0.5+4.2)$.

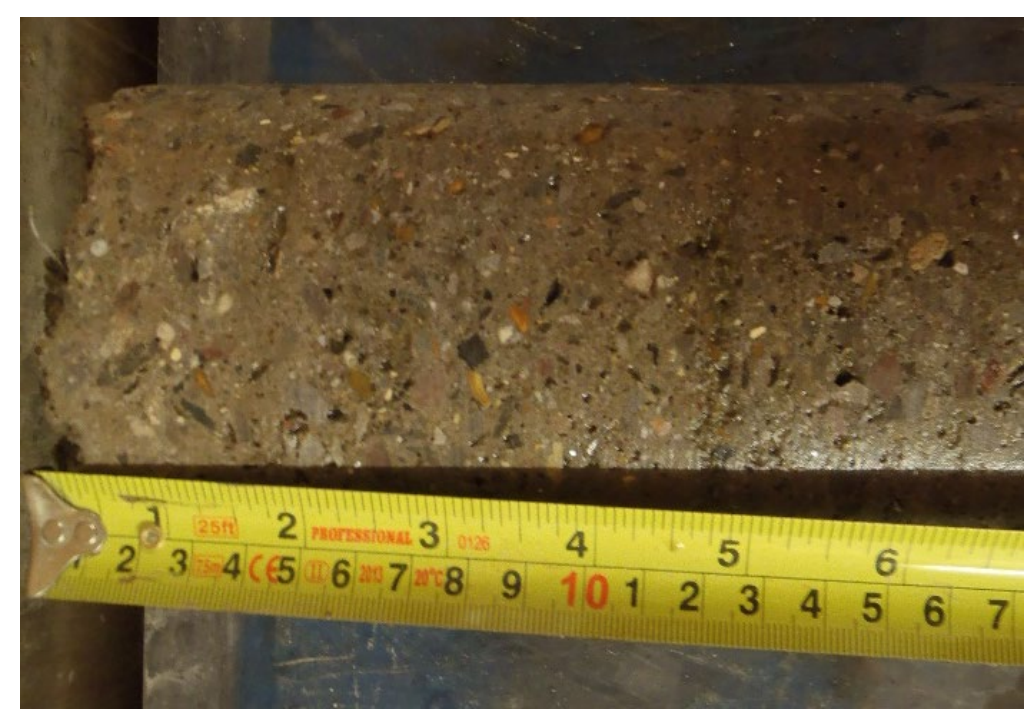

Figure 11 - Photograph showing typical core taken from sprayed concrete lining (photograph Nicholas Trussell)

Holter [33] also used an image analysis (IMA) method [38] to measure the macro porosity and compared it to the closed macro porosity measured with the PF method. This comparison was done on a larger set of specimens from four different tunnel linings. Macro pore volumes were measured to be $4.0-6.0 \%$ from 27 samples, with a mean of $4.5 \%$ measured with the PF method. The image analysis method determined macro pore volume on comparable specimens of $5.7 \%$. If we now define open macroporosity as the difference between macroporosity measured with IMA and with PF we find that the open macro porosity makes up $21 \%$ of the total macroporosity $(5.7-4.5) / 5.7$ of those specimens. Hence open macro porosity, depending on the test method, is in the order of $11-21 \%$ of the total porosity.

Opsahl [20] used microscopic analysis following [39] with an automated camera procedure on a total of 21 different mixes sprayed in full scale on both tunnel linings and test panels. He measured 3.6 to $6.5 \%$ air void content of which most were irregularly shaped compaction voids larger than 300 microns as determined by image analysis. 
Macro pores can be greater than $10 \mathrm{~mm}$ in size for cores of a "good" quality [33]. Cores of poorer quality may have far larger macro pores. A high content of irregular macro pores is likely to increase the permeability of the sprayed concrete due to the increased probability the pores percolate.

From percolation theory we know that the critical volume fraction for percolation, $p_{c}$, of monospheres is $28 \%$ of volume according to Garboczi et al [40]. Elongated pore shape reduces $p_{c}$. Ellipsoids of length/width ratio of $20 / 1$ percolate at $4 \%$ of volume. At length width ratio of $50 / 1, p_{c}$ is $1.5 \%$ of volume and at ratio $100 / 1$ it is only $0.6 \%$ of volume.

Sprayed concrete permeability can be affected by percolation in two ways. Firstly, the shape of the macro pores seen in sprayed concrete is very angular so they are likely to percolate. Secondly, the interfacial transition zone (ITZ) is known to be more permeable than bulk concrete permeability. Therefore $0.6 \%$ of volume as fibres with length/width ratio of 100/1 can increase the permeability. Both factors could lead to a reduction in the durability of the sprayed concrete. This is especially important for tunnel linings, where a high permeability enables groundwater, which may be aggressive to the concrete, to flow through the lining. Though a recent study of air voids in an asphalt concrete material using CT scanning [41] was used to determine interconnectivity between air voids, showing that not all interconnective air voids are valid for permeability.

Furthermore, strength depends on the porosity of the concrete. A $2 \%$ increase in void ratio can decrease the compressive strength by $10 \%$ [26].

An interesting comparison is that the features of the porosity in cold sprayed metals [42] are very similar to the macropore structure in sprayed concrete. Perhaps the relative size of the pores scales to the relative size of the particles in the two different materials.

\section{2}

\section{Permeability}

Opsahl [20] performed hydraulic conductivity tests on sprayed concrete specimens with water pressure of 4-8 $\mathrm{MPa}$. Whilst permeability was found to vary largely, the lowest values measured were $2 \times 10^{-14} \mathrm{~ms}^{-1}$ on concrete drilled from panels sprayed with $\mathrm{w} / \mathrm{c}=0.35$ with fibres but without accelerator. With accelerator, fibre and higher $\mathrm{w} / \mathrm{c}=0.47$ as low values as $4 \times 10^{-14} \mathrm{~ms}^{-1}$ were reported. For some other specimens much higher values were measured. Poor curing and fibres were mentioned as possible explanations for the variation. Opsahl [20] also used the water penetration method to test permeability. He measured water penetration depths of maximum $7 \mathrm{~mm}$ for specimens from tunnel linings, subjected to pressure of $0.5 \mathrm{MPa}$ on one side over 14 days. For specimens from test panels, subjected to pressure of $0.8 \mathrm{MPa}$ on one side for 24 hours he measured water penetration depths in the range of $10-70 \mathrm{~mm}$.

Holter [33] performed hydraulic conductivity measurements with $0.5 \mathrm{MPa}$ water pressure on sprayed concrete without imperfections (i.e. cracks). He measured water permeability of 35 sprayed concrete specimens from three different tunnels. He measured water permeabilities between $3.3 \times 10^{-11}$ and $9.6 \times 10^{-12} \mathrm{~ms}^{-1}$ in four of the specimens, whilst measuring zero water flow through the remaining specimens. With the sensitivity of the equipment being $5 \times 10^{-14} \mathrm{~ms}^{-1}$ he concluded that crack free and well compacted sprayed concrete can have a very low water permeability of less than $5 \times 10^{-14} \mathrm{~ms}^{-1}$. 
Based on this it seems that if one can avoid too high $\mathrm{w} / \mathrm{c}$ ratio, too much variation in compaction, cracking and poor curing it is possible to produce low permeable tunnel linings with conventional wet sprayed concrete.

\section{3}

\section{Durability}

The durability of concrete is a large subject and is only covered briefly here. Whilst durability of sprayed concrete depends on the type of environment that the concrete is exposed to, it also depends on water transport in the sprayed concrete, which is discussed in Sections 5.1 and 5.2.

Accelerated freeze-thaw testing of sprayed concrete has been reported by several, for example by Opsahl [20], Shrader and Kaden [32] and Holter [33]. These studies showed that entrained air voids of the right size and/or very high strength can work to protect sprayed concrete against frost deterioration in severe testing. It was also shown that, as for conventional concrete, the critical dilation test can be used to assess whether a given capillary saturated state will cause internal frost damage. The principle of both type of environment (load: frost, saturation, salt, etc) and material (resistance: strength, air voids, permeability, etc) determine durability.

Hagelia [43] studied chemical degradation of sprayed concrete cores sampled from tunnel linings up to age of about 25 years with variable degrees of deterioration. He found that a w/b ratio of 0.4 and a low capillary porosity, less than $20 \%$, are good properties for the durability of sprayed concrete. He found that capillary porosities of 18 to $20 \%$ seemed to largely prevent the diffusion of saline waters and corrosion of the specimens. The main deterioration mechanisms were found to be chemical and biological degradation of the cement paste in thin (less than $80 \mathrm{~mm}$ thickness) sprayed concrete linings with poor adhesion to the substrate rock.

6.

\section{CONCLUSIONS}

- We propose a definition of "sprayability" that relates the application to the development and the final properties of the hardened sprayed concrete. "Sprayability" is governed by the concrete constituents, proportioning and application mechanics.

- The rheology of concrete is important to enable pumping of fresh concrete. If the concrete cannot be pumped, then it cannot be sprayed.

- The addition of set accelerator at the nozzle is essential to reduce the set time of the sprayed concrete and enables thickness of the sprayed concrete to build up on the substrate. The reaction of the set accelerator with the cement paste gives high early age strength but is detrimental to long term strength.

- Incorporating fly ash into the paste improves long term strength due to the pozzolanic reaction between the silica in the fly ash and calcium hydroxide to produce more calcium silicate hydrate (CSH). Inclusion of fly ash reduces the rate of strength development. This has been compensated for using a hardening accelerator. It has recently been proven possible to spray high fly ash concrete by the wet process (fly ash content up to $33 \%$ of the cement content by mass). 
- There is greater mass density at the centre of the spray cone. Furthermore there is a greater concentration of aggregate at the centre of the spray cone, with a higher proportion of paste at the edge. The nozzle operator should therefore manipulate the nozzle in small, circular movements to ensure even distribution and consistency of sprayed concrete. It is not fully understood how spraying mechanics affect the compaction of the sprayed concrete.

- There is a higher proportion of aggregate, and particularly fibres, in sprayed concrete rebound.

- Very few shrinkage measurements of in-situ sprayed concrete exist. From observed cracks in tunnel linings sprayed directly onto the rock, shrinkage seems to be the main cause of cracking. Whether the observed shrinkage cracking is due to plastic, early age or drying shrinkage is still under investigation.

- Measurements of macro porosity show that 10 to $20 \%$ of the macro pores are open.

- Low permeabilities of less than $2 \times 10^{-14} \mathrm{~ms}^{-1}$ are possible to achieve in uncracked sprayed concrete. Cracks and compaction voids cause higher permeabilities of sprayed concrete.

\section{ACKNOWLEDGMENT}

This paper/presentation is a part of the research project "Sprayed sUstainable PErmanent Robotized CONcrete tunnel lining (SUPERCON)" financed by the Research Council of Norway (project no. 294724), in cooperation with industrial partners Andersen Mek. Verksted, BASF, Bever Control, Bekaert, Elkem, Entreprenørservice, NORCEM, SWECO Norge, Veidekke, Wacker Chemicals Norway. Research partners in SUPERCON are NGI, NTNU and SINTEF. The following project owners support the project; Bane NOR, Nye Veier and the Norwegian Public Roads Administration.

\section{REFERENCES}

1. Jolin M, Melo F \& Bissonnette B: "Concrete durability applied to sprayed concrete mixture design". Proceedings, $7^{\text {th }}$ International Symposium on Sprayed Concrete, Sandefjord, Norway, June 2014, pp. 233-244.

2. Jolin M, Burns D, Bissonnette B, Gagnon F \& Bolduc L-S: "Understanding the pumpability of concrete". Proceedings, Shotcrete for underground support XI, Davos, Switzerland, June 2009.

3. Banthia N, Trottier J-F \& Beaupre D: "Steel fibre reinforced wet-mix shotcrete: comparisons with cast concrete". Journal of Materials in Civil Engineering, Vol. 6, No. 3, 1994, pp. 430-437.

4. Beaupré N: "Rheology of high performance shotcrete". PhD thesis, University of British Columbia, Department of Civil Engineering, Vancouver, Canada, 1994, 265 pp.

5. Mørtsell E: "The effect of the constituent materials on the rheology of fresh concrete". $\mathrm{PhD}$ thesis, Norwegian University of Science and Technology, Department of Structural Engineering, Trondheim, Norway, 1996, 301 pp. (In Norwegian). 
6. Banthia N: "Sprayed concrete (shotcrete)", Chapter 4, "Developments in the Formulation and Reinforcement of Concrete" (edited by Mindess S), Woodhead Publishing Limited, Cambridge, UK, 2008, pp. 98-113.

7. Myren S, Hagelia P \& Bjøntegaard Ø: "The ban of polymer fibre in FRSC in Norwegian road tunnels". Proceedings, $8^{\text {th }}$ International Symposium on Sprayed Concrete, Trondheim, Norway, June 2018, pp. 257-260.

8. Standard: EN 206, "Concrete - Specification, performance, production and conformity", 2013.

9. "Bukte lavkarbon sprøyte-betong på bybaneprosjekt" (Use of low-carbon sprayed concrete on an urban railway project). Byggeindustrien magazine, NR. 19 - 2019, p 96. (In Norwegian).

10. Tattersall \& Banfill: "The Rheology of Fresh Concrete", Pitman Books Ltd, London, UK, 1983.

11. Kaplan D, de Larrard F \& Sedran T: “Avoidance of Blockages in Concrete Pumping Process". ACI Materials Journal, May-June 2005, 102-M21, pp. 183-191.

12. Bartos P, Sonebi M \& Tamimi A K: "Workability and rheology of fresh concrete: compendium of tests", Report of RILEM technical committee TC145 WSM, RILEM Publications, 2002.

13. Standard: EN 12350-5, "Testing of fresh concrete - Part 5: Flow table test", 2019.

14. Standard: EN 12350-2, "Testing of fresh concrete - Part 2: Slump test", 2019.

15. Myrdal R: "Accelerating admixtures for concrete - state of the art", SINTEF report, Trondheim, Norway, 2007.

16. Choi M, Roussel N, Kim Y \& Kim J: "Lubrication layer properties during concrete pumping". Cement and Concrete Research, Vol. 45, 2013, pp. 69-78.

17. Ginouse N \& Jolin M: "Investigation of spray pattern in shotcrete applications". Construction and Building Materials, Vol. 93, 2015, pp. 966-972.

18. Ginouse N, Jolin M \& Bissonnette B: "Effect of equipment on spray velocity distribution in shotcrete applications". Construction and Building Materials, Vol. 70, 2014, pp. 362-369.

19. Ginouse N \& Jolin M: "Characterization of placement phenomenon in wet sprayed concrete". Proceedings, $7^{\text {th }}$ International Symposium on Sprayed Concrete, Sandefjord, Norway, June 2014, pp. 173-183.

20. Opsahl O A: "A study of a wet-process shotcreting method - Volume I". Report BML 85.101, $\mathrm{PhD}$ thesis, Norwegian Institute of Technology, University of Trondheim, Division of Building Materials, Trondheim, Norway, $226 \mathrm{pp}$.

21. Reinhold M \& Wetzig V: "Influence of air-flow at nozzle-distance on sprayed concrete properties". Proceedings, $7^{\text {th }}$ International Symposium on Sprayed Concrete, Sandefjord, Norway, June 2014, pp. 320-329.

22. Publication no. 7: "Sprayed Concrete for Rock Support". Norwegian Concrete Association, Oslo, Norway, 2011.

23. Kauffman J, Frech K, Schuetz P \& Münch: "Rebound and orientation of fibers in wet sprayed concrete applications". Construction and Building Materials, Vol. 49, 2013, pp. 15-22.

24. Austin S, Goodier C \& Robins P: "Low-volume wet-process sprayed concrete: pumping and spraying". Materials and Structures, Vol- 38, 2005, pp. 229-237.

25. Standard: EN 14487-1, "Sprayed concrete - Part 1: Definitions, specifications and conformity", 2012.

26. Neville AM: "Properties of Concrete", $4^{\text {th }}$ Edition, Longman Group Limited, Harlow, England, 1995.

27. Taylor H: "Cement Chemistry", $2^{\text {nd }}$ Edition, Thomas Telford Publishing, London, UK, 459 pp. 
28. Salvador R, Cavalaro S, Segura I, Figueiredo A \& Pérez J: "Early age hydration of cement pastes with alkaline and alkali-free accelerators for sprayed concrete". Construction and Building Materials, Vol. 111, 2016, pp. 386-398.

29. Beck T: "Effect of fresh concrete temperature and temperature in surroundings on compressive strength development in sprayed concrete". Proceedings, $7^{\text {th }}$ International Symposium on Sprayed Concrete, Sandefjord, Norway, June 2014, pp. 50-55.

30. Cepuritis R: "Norbetong standard test method: determination of setting time for sprayed concrete containing accelerating admixture", unpublished, 2009.

31. Standard: EN 196-1, "Methods of testing cement - Determination of strength", 2016.

32. Shrader E \& Kaden R: "Durability of shotcrete". Proceedings, Concrete Durability International Conference, Volume 2, American Concrete Institute, Detroit, USA, 1987, pp. 1071-1101.

33. Holter: "Properties of waterproof sprayed concrete tunnel linings". 197, PhD thesis, Norwegian University of Science and Technology, Department of Geology and Mineral Resources Engineering, Trondheim, Norway, 2015, 167 pp.

34. Bryne L E, Ansell A \& Holmgren J: "Investigation of restrained shrinkage cracking in partially fixed shotcrete linings". Tunnelling and Underground Space Technology, 42, 2014, pp. 136-143.

35. Menu B, Jolin M, Bissonnette B \& Molez L: "Évaluation de la sensibilté à la fissuration des bétons projetés au jeune âge" (Assessment of the sensitivity to cracking of sprayed concrete at a young age). Proceedings, Conférence International Francophone NoMaD 2018.

36. Punkki J \& Sellevold E J: "Capillary suction in concrete: effects of drying procedure". Nordic Concrete Research, Vol. 15, 1994, pp. 59-74.

37. Sellevold E J \& Farstad T: "The PF-method - a simple way to estimate the w/c-ratio and air content of hardened concrete". Proceedings, Construction materials: performance, innovations and structural implications, Vancouver, Canada, 2005, $10 \mathrm{pp}$.

38. Fonseca P C \& Scherer G W: "An image analysis procedure to quantify the air void system of mortar and concrete". Materials and Structures, Vol. 48, 2015, pp. 3087-3098.

39. ASTM Standard C457.C457M-11: Standard test method microscopical determination of parameters of the air-void system in hardened concrete, ASTM International, West Conshohocken, PA, 2003.

40. Garboczi E J, Snyder K A, Douglas J F \& Thorpe M F: "Geometrical percolation threshold of overlapping ellipsoids". Physical Review E, Vol. 52, No. 1, 1995, pp. 819-828.

41. Zhao Y, Wang X, Jiang J \& Zhou L: "Characterisation of interconnectivity, size distribution and uniformity of air voids in porous asphalt concrete using X-ray CT scanning images". Construction and Building Materials, Vol. 213, 2019, pp. 182-193.

42. Hodder K J, Izadi H, McDonald A G \& Gerlich AP: "Fabrication of aluminium-alumina metal matrix composites via cold gas dynamic spraying at low pressure followed by friction stir processing". Materials Science \& Engineering, A 556, 2012, pp. 114-121.

43. Hagelia P: "Durability of sprayed concrete for rock support - a tale from the tunnels. Proceedings". $8^{\text {th }}$ International Symposium on Sprayed Concrete, Trondheim, Norway, June 2018, pp. 172-187. 